\title{
The Cultural Psychological Motivations and Strategies for the Development of Cultural Industry: an Interpretation of Social Cultural Psychology Based on the Engel's Theorem
}

\author{
Jianing Chen \\ School of Psychology, School of Education, Shenzhen University Teachers College, Shenzhen 528000, China \\ Email: 704923214@qq.com
}

\begin{abstract}
The cultural industry is an industry that takes culture and creativity as the core of product design, faces the masses, and takes the cultural identity of the masses and the cultural and psychological characteristics of social groups as reference factors for marketing and development. The key to its success lies in the perception and use of its social and cultural psychology. And Engel's theorem is a typical theory that reflects the economic and cultural level and the psychological state of of the country and local people. The analysis of cultural industries based on it can also help contemporary cultural creative workers to more intuitively understand the social market needs and maintain the healthy growth of the cultural industry.
\end{abstract}

Keywords: culture industry, Engel's theorem, sociocultural psychology

\section{Introduction}

The emergence of the cultural industry comes from the demand for cultural consumption generated by the masses on a certain economic basis and the psychological desire for social identity and communication behavior based on cultural images. As an industry that grasps the psychological and cultural needs of the masses, the design and dissemination of cultural products and the scale development of the cultural industry are inseparable from the grasp of the common characteristics of regional social culture and psychology. ${ }^{[1]}$ The generation of social and cultural psychology is a complex process, and the characteristics embodied by social and cultural psychology also affect the development of the cultural industry from various aspects.

\section{Cultural psychological factors in the cultural industry}

Cultural psychology is a subject that crosses cultural studies and psychological studies. It was first proposed by Davos and Shipler. The richness of culture and the initiative of directors make it extremely close to people's psychological state. ${ }^{[2]}$ The cultural industry that regards "cultural value" as the core of product and industry development will inevitably reflect clear cultural psychological factors, which are mainly reflected in the following three aspects:

The first is the consumption of cultural products and the psychology of cultural awareness. The core of cultural psychology research is the process of human cognition of the world. The formation of cultural awareness requires a practical approach, and cultural products are drawn from the national historical and cultural background and contemporary human society. The commodity of life is the embodiment of the cultural consciousness of social groups. At the same time, the advantages and disadvantages of cultural products will also affect the development of the cultural awareness of the masses. ${ }^{[3]}$

The second is the cultural product consumption and cultural emotional psychology. The creator of the book "Clash of Civilizations and Reconstruction of the World Order" Huntington once proposed that "cultural identity is one of the most important things for people". ${ }^{[4]}$ The masses' consumption of cultural products is largely due to the "cultural identity" brought about by the inclusion of regional or national cultural traditional imagery symbols in products, following a certain type of social and cultural boom.

Third, the cultural industry development and cultural innovation psychology: In addition to expanding the scope of cultural industries, Throsby will highlight the concept of "creativity" and use the concentric circle model to combine "creativity", "cultural symbolic value" and "business" The analysis of the adaptation relationship between the proportion of the proportion of cultural creativity and the development of industrial commercialization is interconnected, showing the intuitive relationship between the "cultural value" and "economic value" of cultural industry products ${ }^{[5]}$. Marx and Engels 
clearly emphasized the inevitability of cultural progress in the development of the country and the fundamental role of social practice in the promotion of cultural innovation, and the cultural creative industry's emphasis on "creativity" is a direct manifestation of this concept.

\section{Engel's theorem and the embodiment of social and cultural psychology in cultural industry}

\subsection{The economic foundation determines the driving force of regional cultural consumption}

Engel's theorem is considered as one of the "most scientific theories of social development analysis", and its importance to cultural consumption factors is clearly stated. Engel's theorem mainly includes two parts. The first point is that the proportion of a family's expenditure on food purchases to the total expenditure will decrease as the total household income increases; the second point is the expenditure of a family on cultural consumption. The proportion of total expenditure will increase with the increase of total household income ${ }^{[6]}$. Engels believes that the economic development of society is the basis for the development of spiritual civilization in the country, such as politics, culture, art, religion, etc., and the development of economy and spiritual civilization is not independent. It reflects various social ideologies, upper levels Interactive relationship between building and economic foundation ${ }^{[7]}$. The impact of different economic foundations on social ideological trends will also lead to different social and cultural conditions, thus reflecting the differences in demand for cultural consumption in different regions. The generation of culture comes from a certain socio-economic foundation and a specific social system. Therefore, the development of the cultural industry must match the local economic development. Only on the basis of a relatively solid economic foundation can the masses have enough energy, capital and motivation to carry out Corresponding cultural consumption.

\subsection{Cultural consumption demand has stimulated cultural creativity}

The cultural industry, as an industry that uses the cultural needs of the masses to create business value, determines the nature of its market economy by its own nature, and market demand is the core element that determines the development of the market economy. In the process of the formation and development of the cultural industry, It is the impetus for cultural industry organizations to stimulate their own cultural creativity. From the perspective of the British cultural tourism industry, its development is caused by the changes in the urban living environment of industrial cities and the longterm life of the middle class in industrial industries and cities. It is inspired by the desire for nature and past social life and culture. Fan culture researcher Jenkins ${ }^{[7]}$ and popular culture researcher Feske ${ }^{[8]}$ believe that the development of the mass cultural industry depends largely on the attachment of fan culture, which is mainly reflected in the group, eagerness, and enthusiasm generated by the pursuit of certain types of cultural images (such as rock music, literary works, etc.) by certain types of people. Consumption behavior is regular, and in the process of cultural consumption, the people are concerned about the satisfaction of the cultural needs of their loved cultural image and the cultural identity brought about by the communication behavior in the consumption process, not the commodity itself. Therefore, the public's pursuit of the satisfaction brought by cultural consumption is the key to the development of cultural products and the development of cultural creative industries. Regardless of the creative form of cultural products, the control of its internal cultural image and the needs of mass cultural consumption.

\subsection{The characteristics of social cultural psychology and the challenges facing the development of cultural industry}

Engel's theorem regards the proportion of cultural consumption in household consumption as an aspect that reflects the status of social development, and also recognizes the interaction between social and cultural factors, economic factors and social development. The study of historical materialism emphasizes the direct influence of social and cultural psychology on social customs and cultural trends. Toynbee regards human subconsciousness as an important driving force of cultural practice in the study of social and cultural psychology, and subconsciousness can be divided into two parts: "personal consciousness" and "ethnic consciousness". The latter is Formed by long-term social and cultural accumulation ${ }^{[9]}$. The cultural industry is aimed at the broad masses of society, and the emotional satisfaction of cultural people for cultural identity is the core value of the spiritual level. Therefore, the control of social cultural psychology in the entire industry construction has become A question that runs through. However, social and cultural psychology has certain individuality and pluralistic characteristics in personal consciousness, especially in the current era of frequent cultural exchanges in the world, the differences in cultural values brought about by the growth environment of the masses, and the impact of foreign culture The new consumption standards for cultural products have created many challenges for the cultural industry in 
the discovery of its own cultural characteristics and the satisfaction of the market's diverse cultural needs; from the perspective of ethnic consciousness, the generation of cultural psychology depends on the long-term history of the country. It has a certain lag and unity, and the discovery and control of past traditional cultural factors by cultural products, as well as the need for innovative power and the choice of innovative forms in this period are also proposed for the promotion of cultural industry creativity.

\section{Enlightenment of Engel's theorem to the development of cultural industry}

\subsection{Frankfurt School, Engel and cultural industry}

The concept of the cultural industry was not originally derived from the perception of the cultural consumer market in business or culture, but originated from the Frankfurt School in Germany. Adorno defines the cultural industry in the art of Dialectics of Enlightenment as a large-scale, creative commercial production of cultural products based on modern industrial thinking. In the book "Rethinking Cultural Industry", it clarifies the inevitable contradiction between the development thinking of the cultural industry with "profit creation" as its goal and the nature of culture and art. ${ }^{[10]}$ Replicating cultural products that constantly change their essence in accordance with market demand and mainstream ideology will control the cultural aesthetics of the masses to a certain extent. The Frankfurt School's critique of the cultural industry originated from the American popular entertainment industry in the last century, and its worries about the "anti-cultural phenomenon" brought about by commercialization are not unreasonable. For China, which is currently focusing on the construction of a market economy and the promotion of the cultural industry, how to plan the development direction of the cultural industry in accordance with the Frankfurt School and the core of Engel's Theorem has become an urgent issue. ${ }^{[11]}$

\subsection{Thoughts on the development of cultural industry based on Engel's theorem}

\subsubsection{The grasp of cultural needs is the first task}

The production of cultural products must not only deeply explore the country's historical and cultural resources, but also objectively look at the market characteristics and economic benefits of cultural industries as part of a market economy. The macro-control of the cultural industry must be based on the cultural consumption needs of the masses. Only when the mass consumer's consumption needs for specific cultural types or products and services are met, and the characteristics of the cultural trends of the masses in the contemporary social and cultural context are well grasped, can the cultural industry match the market. Adapt to and spread advanced cultures that truly guide social and cultural development, and realize a real and healthy income-generating mechanism. ${ }^{[12]}$

\subsubsection{The awakening of cultural identity is a necessary approach}

Cultural identity is a reflection of the "ethnic consciousness" in the subconscious of the social life of the masses. It is the internal driving force of the cultural consumption behavior of the masses and the most desired emotional gain. Therefore, cultural and creative products must truly meet the needs of the market. The awakening of cultural identity is essential. ${ }^{[13]}$ The awakening of cultural identity psychology can be divided into two levels. First, in the design of cultural products, we should start from the history and culture of the country or nation, and the current cultural trend of social groups, in line with the pursuit of mass cultural identity. In the process of excavating the cultural core of cultural products, it is necessary to discover outstanding cultures, use cultural products to counteract the development of social cultural psychology, and guide the formation of correct cultural identity and cultural self-confidence.

\section{Conclusion}

As an emerging industry based on a certain socio-economic foundation in the construction, the cultural industry is inseparable from the daily cultural life and cultural psychology of the public, as well as the cultural heritage of the nation. At the same time, the goods and cultural activities produced by the cultural industry will also adversely affect society. Cultural psychological development has an impact. Therefore, the cultural industry must be carried out in an innovative form on the basis of respecting the cultural origin. We should carry out industrial development planning based on the characteristics of the cultural psychology of the masses and the cultural consumption needs of the market, and should not sacrifice the core value of culture or ignore social culture demand. 


\section{References}

[1] Department for Culture Media and Sport (DCMS). Creative Industries Mapping Document. 2001.

[2] Luo Bing, Wen Simei. Comparative Study on the Extension and Connotation of the Concepts of Cultural Industry and Creative Industry. Gansu Social Science. 2006; 5: 119-122.

[3] Throsby, D. Economics and Culture. London: Cambridge University Press; 2001.

[4] Samuel Huntington. Clash of Civilizations and Reconstruction of World Order. Beijing: Xinhua Publishing House; 2010.

[5] Zhang Hongwu, Wang Yaxiong. Applicability of Engel's coefficient and evaluation of residents' living standards. Forum on Statistics and Information. 2005; 1: 21-24.

[6] Hu Haibo. Research on Marx and Engels'Cultural Views. Northeast Normal University; 2010.

[7] Jenkins, H. Textual poachers: Television fans and participatory culture. New York: Routledge Press; 1992.

[8] Chen Lixu. "Understanding Popular Culture" and Contemporary China. Zhejiang Social Science. 2013; 4: 19-27.

[9] Adorno, Dai Yun. Art and Society. Theoretical Studies of Literature and Art. 1988; 03: 95-99.

[10] AAdorno, T. W. and Rabinbach, A. G. Culture industry reconsidered. New German Critique. 1975; 6: 12-19.

[11] Fu Rui. Toynbee's Thoughts on Sociocultural Psychology and Social Change and Its Enlightenment. Learning and Exploration. 2012; 4: 38-40.

[12] Jiang Bo. Policy Orientation of Social Psychological Adjustment, Cultural Product Consumption and Cultural Industry Development. Studies of Socialism with Chinese Characteristics. 2007; 5: 48-51.

[13] Zhang Xiaoming. New situation, new thinking and new strategy of the cultural industry. People's Forum. 2017; 31: 96-97. 